\title{
A CASE OF TREACHER COLLINS SYNDROME
}

\author{
Ulusal S ${ }^{1, *}$, Gürkan $H^{1}$, Vatansever $\ddot{U}^{2}$, Kürkçü K ${ }^{3}$, Tozkir $\mathrm{H}^{1}$, Acunaş BA ${ }^{2}$
}

*Corresponding Author: Dr. Selma Ulusal, Department of Medical Genetics, Trakya University, Faculty of Medicine, Edirne, Turkey; Tel.: +90-284-235-76-42-2346; Gsm: +90-533-2504116; Fax: +90-284-235-27-30; E-mail: selmaulusal@trakya.edu.tr

\begin{abstract}
Treacher Collins syndrome (TCS) is an autosomal dominant disorder of craniofacial development with an incidence of 1/50,000 live births. Mutations of the TCOF1 gene have been found to be responsible for most cases of this mandibulofacial disorder. Here we report TCS in an individual who has a heterozygous c.1021_1022delAG deletion in exon 7 of the TCOF1 gene (NG_011341.1). This is the second Turkish patient with a severe TCS phenotype resulting from a de novo c.1021_1022delAG mutation.
\end{abstract}

Keywords: TCOF1 gene; Treacher Collins syndrome (TCS); Mandibulofacial dysostosis; De novo mutation.

\section{INTRODUCTION}

Treacher Collins syndrome (TCS, OMIM 154500), also known as mandibulofacial dysostosis, is a rare developmental disorder of the craniofacial region and is one of the most severe forms of mandibulofacial dysostosis syndromes [1]. The disease was named after the report of Treacher Collins in 1900 [2] and reviewed in detail by Franceschetti and Klein in 1949 [3]. The estimated incidence is about $1 / 50,000$ live births [1].

\footnotetext{
${ }^{1}$ Department of Medical Genetics, Trakya University, Faculty of Medicine, Edirne, Turkey

${ }^{2}$ Department of Pediatrics, Trakya University, Faculty of Medicine, Edirne, Turkey

${ }^{3}$ Burç Genetik Diagnosis Center, Istanbul, Turkey
}

Treacher Collins syndrome is transmitted in an autosomal dominant manner, but only $40.0 \%$ of cases are familial $[1,4]$. Mutations of the TCOF1 gene, which is located on 5q32-q33.1, have been found to be responsible for most of the cases. The TCOF1 gene encodes the treacle protein, a serine/alanine rich protein predicted to have an important role in ribosome biogenesis [5]. More than 130 mutations have been reported in the TCOF1 gene. Deletions ranging from 1 to 40 bases are the most common causes of TCS [6].

Clinical manifestations of TCS include downward slanting of palpebral fissures, hypoplasia of the zygomatic complex and the mandible, complete or partial cleft palate, coloboma of the lower eyelids, and atresia of external ear canals with abnormalities of the external ears accompanied by conductive hearing loss $[7,8]$.

The phenotypic variability of the clinical symptoms in TCS is a major obstacle for its diagnosis. Although there is as yet no clear explanation, genotype and phenotype discordance have been reported in some studies $[8,9]$. Phenotypic expression of the syndrome is so mild in some individuals that they cannot be distinguished physically, while some others experience sudden death after birth due to the respiratory distress [10].

\section{CASE REPORT}

The patient was a 9-day-old female with multiple congenital anomalies. She was the first child of a non consanguineous couple of Turkish origin. The moth- 


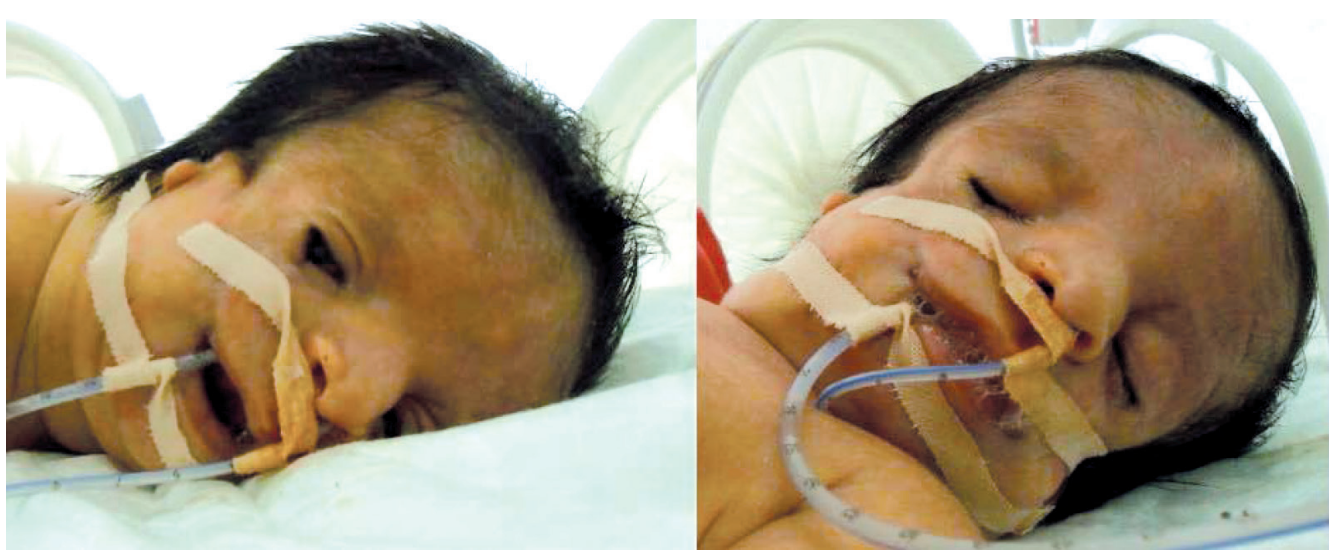

Figure 1. Hypoplasia of the zygomatic complex and downward slanting palpebral fissures with coloboma of lower eyelids and preauricular tags in this case (9-day-old female patient).

er was 33 years old and the father was 35 years old. There was no family history. Mother was under treatment for hypothyroidism during pregnancy, and a history of polyhydramnion existed. The infant was born via Cesarean section at term. She was $3100 \mathrm{~g}$ and 49 cm tall; head circumference was $34 \mathrm{~cm}$. Downward slanting of palpebral fissures with bilateral absence of zygomatic bones were accompanied by coloboma of both lower eyelids. The cystic appearance of the left upper eyelid was examined (Figure 1). Eyelashes were absent in the medial part of both lower eyelids. The patient's nose was broad with a wide nasal bridge and a flattened root. Microtia and external ear abnormalities with conductive deafness and choanal atresia were noted. She had preauricular tags. There was complete cleft palate with retrognathia and micrognathia. A tracheostoma was done at the age of
2.5 months. On examination at the age of 4.5 months, motor developmental delay was observed.

Transcranial ultrasonography was normal. Heparinized and EDTA blood samples from the parents and from the patient were taken after informed consent forms were obtained. The GTG-banded chromosomes of the cultured lymphocytes revealed a 46,XX karyotype. DNA samples were extracted from EDTA-blood of the family members. Sanger sequencing of the TCOF1 gene of the patient revealed a heterozygous c.1021_1022delAG deletion in exon 7 of the TCOF1 gene (NG_011341.1). The deletion causes a frameshift mutation and a premature stop codon at position 348 (p.Ser341Glnfs*7; NM_001135243.1) of the treacle protein. After sequencing of both parents for the mutation site, we determined the mutation arose as a de novo muta-

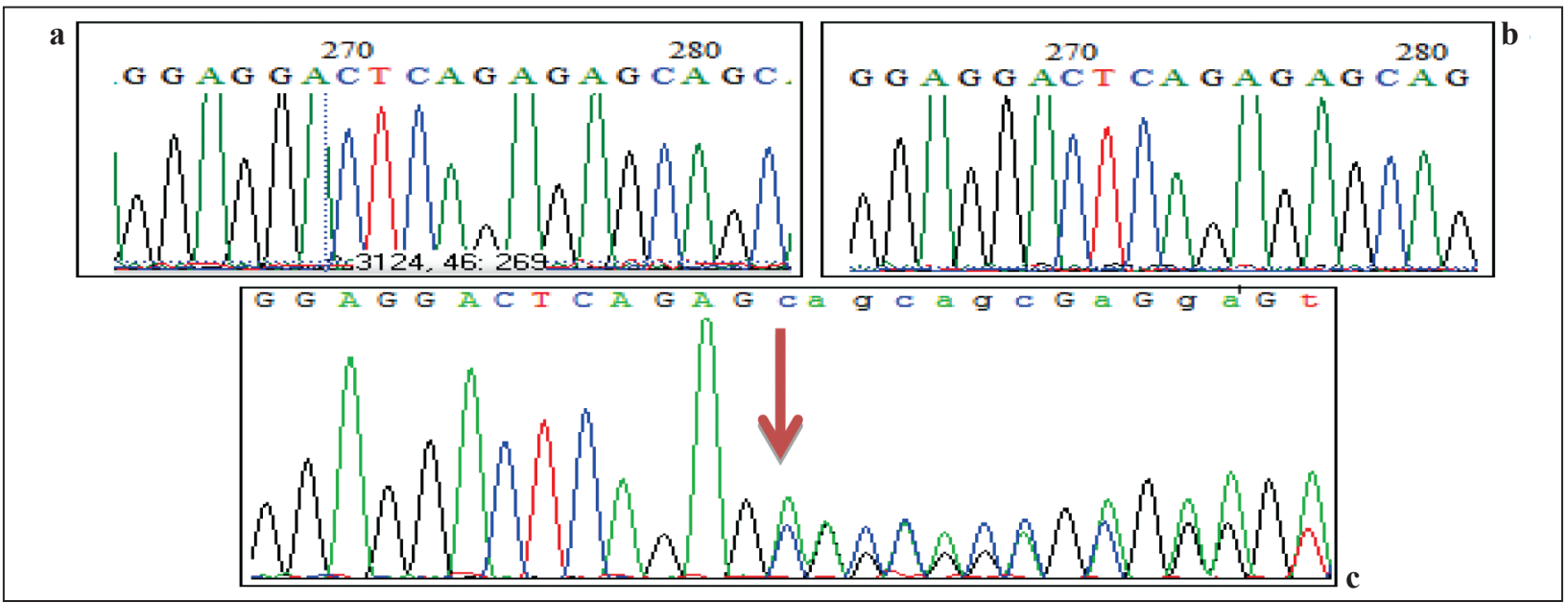

Figure 2. Electropherograms of the c.1021_1022delAG mutation site of the mother (a), the father (b) and the patient (c). A heterozygous $2 \mathrm{bp}$ deletion causes a frameshift in the patient. 
tion in our patient (Figure 2). Primer sequences and polymerase chain reaction (PCR) conditions can be shared upon request.

\section{DISCUSSION}

Clinical manifestation of TCS is widely variable, even in cases with the same mutation. Hypoplasia of zygomatic bones and downward slanting of palpebral fissures are the most common findings, but in some cases, these minimal diagnostic criteria may not be distinguished or evident during physical examination. No clear explanation exists for the different presentations of TCS. The wide variability has been attributed to modifier genes, epigenetic factors and the role of the non mutated alleles [8,9].

The patient described in this report was diagnosed on physical examination; the TCS diagnosis was sub- sequently confirmed by molecular analysis. She has a severe phenotype with a score of 18/20 when we evaluate her clinical characteristics according to the scoring system developed by Teber et al. [8].

In the literature, a previous report described four further TCS cases in which the same mutation was present [9]. The clinical characteristics of these cases are summarized in Table 1. As in our patient, one of the four previous cases is also of Turkish origin (Case 1, Table 1). The similarity of the clinical characteristics of the TCS in these two Turkish cases is dramatic. The only criteria that could not be assessed with respect to its similarity is speech development, which could not be evaluated in our patient due to her age. In the prenatal period, both mothers had a history of polyhydramnion, which is a common finding in pregnancies where a newborn is diagnosed with TCS [11-13]. For this reason, in pregnancies in

Table 1. Comparison of clinical characteristics in the five patients with the c.1021_1022delAG mutation. (Table is adapted from Schlump et al. [9].)

\begin{tabular}{|l|c|c|c|c|c|}
\hline Clinical Findings & $\begin{array}{c}\text { Case 1 } \\
{[9]}\end{array}$ & $\begin{array}{c}\text { Case 2 } \\
{[9]}\end{array}$ & $\begin{array}{c}\text { Case 3 } \\
{[9]}\end{array}$ & $\begin{array}{c}\text { Case 4 } \\
{[9]}\end{array}$ & $\begin{array}{c}\text { Case 5 } \\
\text { (this study) }\end{array}$ \\
\hline Sex-Age & M-1 & F-9.5 & M-unknown & M-newborn & F-9-days-old \\
\hline Downward slanting of palpebral fissures & {$[+]$} & {$[+]$} & {$[+]$} & {$[+]$} & {$[+]$} \\
\hline Hypoplasia of zygomatic complex & {$[+]$} & {$[+]$} & {$[+-]$} & {$[+]$} & {$[+]$} \\
\hline Hypoplasia of mandible & {$[+]$} & {$[+]$} & {$[-]$} & {$[+]$} & {$[+]$} \\
\hline Microtia & {$[+]$} & {$[+]$} & {$[-]$} & {$[+]$} & {$[+]$} \\
\hline Lower eyelid coloboma & {$[-]$} & {$[+]$} & {$[-]$} & {$[-]$} & {$[+]$} \\
\hline Atresia of external ear canal & {$[+]$} & {$[+]$} & {$[-]$} & {$[+]$} & {$[+]$} \\
\hline Preauricular tags & {$[-]$} & {$[-]$} & {$[-]$} & {$[-]$} & {$[+]$} \\
\hline Conductive deafness & {$[+]$} & {$[+]$} & {$[-]$} & {$[+]$} & {$[+]$} \\
\hline Choanal stenosis/atresia & {$[+]$} & {$[-]$} & {$[-]$} & {$[+]$} & {$[+]$} \\
\hline Cleft palate & {$[+]$} & {$[-]$} & {$[-]$} & {$[+]$} & {$[+]$} \\
\hline Tracheostoma & {$[+]$} & {$[-]$} & {$[-]$} & {$[-]$} & {$[+]$} \\
\hline Delayed motor development & {$[+]$} & {$[-]$} & {$[-]$} & {$[-]$} & {$[+]$} \\
\hline Delayed speech development & {$[+]$} & {$[-]$} & {$[-]$} & {$[+]$} & unknown \\
\hline Facial phenotype & severe & moderate & very mild & mild & moderate \\
\hline Severity according to $[8]^{c}$ & $17 / 20$ & $12 / 20$ & $4 / 20$ & $14 / 20$ & $18 / 20$ \\
\hline Severe/mild according to the score & severe & severe & mild & severe & severe \\
\hline
\end{tabular}

a Case 2 is the daughter of case 3 .

$\mathrm{b}$ Case 3 is the father of case 2 .

c Severity of phenotypic expression is calculated according to Teber et al. [8] The main clinical features (downward slanting palpebral fissures, lower eyelid coloboma, hypoplasia of zygomatic complex, hypoplasia of mandible, microtia) each carry a score of 2 points; accessory features (cleft palate, atresia of external ear canal, conductive deafness, tracheostoma, choanal stenosis/atresia, preauricular tags, delayed motor development, delayed speech development) each carry a score of 1 point. The facial phenotype score is 2 points if severe, 1 point if mild. The sum of the points provides the severity score. 
which the mother experiences polyhydramnion and findings on ultrasound imaging are abnormal for the facial anatomy, the obstetrician may take the possibility of TCS into consideration.

The remaining three cases also reported to have the c.1021_1022delAG mutation on the TCOF1 gene possess the minimal diagnostic criteria. Two of them are father and daughter from the same family; among five cases with the c.1021_1022delAG mutation, the mildest one is the father. As mentioned in previous reports $[8,9]$, the wide variability in the clinical spectrum among cases in patients who carry the c.1021_1022delAG mutation on the TCOF1 gene reflects the differences in clinical presentation for TCS (Table 1) [8,9]. While all five cases possess at least the minimal diagnostic criteria for TCS, and the high degree of similarity in clinical features for the two severe Turkish cases is obvious, it still seems difficult to suggest the phenotype from the mutation status as usual in TCS.

Declaration of Interest. The authors report no conflicts of interest. The authors alone are responsible for the content and writing of this article.

\section{REFERENCES}

1. Fazen LE, Elmore J, Nadler HL. Mandibulofacial dysostosis (Treacher-Collins syndrome). Am J Dis Child. 1967; 113(4): 405-410.

2. Treacher Collins E. Case with symmetrical congenital notches in the outer part of each lower lid and defective development of the malar bones. Trans Ophtalmol Sec UK. 1900; 20: 190-192.

3. Francheschetti A, Klein D. The mandibulo-facial dysostosis. A new hereditary syndrome. Acta Ophtalmol (Copenh). 1949; 27(2): 143-229.

4. Rovin S, Dachi SF, Borenstein DB, Cotter WB. Mandibulofacial dysostosis, a familial study of five generations. J Pediatr. 1964; 65(2): 215-221.

5. The Treacher Collins Collaborative Group. Positional cloning of a gene involved in the pathogenesis of Treacher Collins syndrome. Nat Genet 1996; 12(2): 130-136.
6. Dixon J, Trainor P, Dixon MJ. Treacher Collins syndrome. Orthod Craniofac Res. 2007; 10(2) 88-95.

7. Marres HAM, Cremes WRJ, Dixon MJ, Huygen PLM, Joosten FBM. The Treacher Collins syndrome. A clinical, radiological, and genetic linkage study on two pedigrees. Arch Otolaryngol Head Neck Surg. 1995; 121(5): 509-514.

8. Teber ÖA, Gillessen-Kaesbach G, Fischer S, Böhringer S, Albrecht B, Albert A, et al. Genotyping in 46 patients with tentative diagnosis of Treacher Collins syndrome revealed unexpected phenotypic variation. Europ J Hum Genet 2004; 12(11): 879-890.

9. Schlump JU, Stein A, Hehr U, Karen T, MöllerHartman C, Elcioglu NH, et al. Treacher Collins syndrome: clinical implications for the pediatrician-a new mutation in a severely affected newborn and comparison with three further patients with the same mutation, and review of the literature. Eur J Pediatr. 2012; 171(11): 1611-1618.

10. Horiuchi K, Ariga T, Fujioka H, Kawashima K, Yamamoto Y, Igawa $\mathrm{H}$, et al. Mutational analysis of TCOF1 gene in 11 Japanese patients with Treacher Collins syndrome and mechanism of mutagenesis. Am J Med Genet. 2005; 134A(4): 363-367.

11. Kopelman JN, Duff P. Treacher-Collins syndrome: an association with polyhydramnios. Mil Med. 1988; 153(9): 485-486.

12. Ruangvutilert P, Sutantawibul A, Susanee-vithayakul P, Limwongse C. Ultrasonographic prenatal diagnosis of Treacher Collins syndrome. $\mathrm{J}$ Med Assoc Thai. 2003; 86(5): 482-488.

13. Pereira DC, Bussamra LC, Arauio Júnior E, Drummond CL, Nardozza LM, Moron AF, et al. Prenatal diagnosis of Treacher Collins syndrome using three-dimensional ultrasonography and differential diagnosis with other acrofacial dysostosis syndromes. Case Rep Obstet Gynecol. 2013; 2013: 203976. doi: 10.1155/2013/203976 Epub 2013 Apr 4. 